\title{
The Research of Space Temperature Distribution in Solid Tower of Extra- dosed Cable-Stayed Bridge
}

\author{
Yanwei Niu ${ }^{1,2, *}$, Yu Zhao ${ }^{1}$, Xiaoxiao $\mathrm{Qu}^{1}$, Qi Yu ${ }^{3}$, and Pingming Huang ${ }^{1}$ \\ ${ }^{1}$ School of Highway, Chang'an University, Xi'an 710064, China; ${ }^{2}$ Loess Region Key Laboratory of Transportation \\ Ministry, Taiyuan 710064, China; ${ }^{3}$ Zhong Zi Hua Ke Traffic Construction Technology Co. Ltd, Beijing 100195, China
}

\begin{abstract}
Based on space temperature field test in solid tower of extradosed cable-stayed bridge, the method to calculate the space temperature field in solid concrete bridge tower is put forward systematically. By defining a series of meteorological parameters and concrete thermal parameters, the bridge tower temperature distribution is gotten. Compared with the experimental data, error is found within $21.38 \%$, which shows that the temperature field algorithm is reasonable. Under the steady temperature field state, bridge tower section temperature distribution is analyzed within 24 hours, the result shows: maximum negative temperature difference appears on sunrise. Maximum negative temperature difference in transverse and longitudinal direction of bridge is $5.1^{\circ} \mathrm{C}$ and $4.2{ }^{\circ} \mathrm{C}$ respectively. The most-positive temperature difference in transverse direction appears at $15 \mathrm{PM}$. The temperature difference value is about $20^{\circ} \mathrm{C}$. This research simulates the temperature distribution in transverse and longitudinal directions of the bridge when maximum negative temperature difference appears in solid concrete bridge towers and provides the curve equation.
\end{abstract}

Keywords: Extradosed cable-stayed bridge, maximum negative temperature difference, model test, temperature distribution, thermal analysis, solid tower.

\section{INTRODUCTION}

Because of the simple structure and convenient construction, solid concrete bridge tower is widely used in extradosed cable-stayed bridge. Concrete structures, in the natural environment, withstand radiation from the sun and effect of environment temperature change for a long time. Because the heat transfer performance of concrete is poor, as in the concrete structure, there is a large temperature gradient, which can cause temperature stress and sometimes lead to the concrete crack. Concrete bridge tower is an important part of extradosed cable-stayed bridge, so the concrete crack caused by temperature effect cannot be ignored. At present, there have been many studies about the effect of temperature on concrete bridge tower. By continuously monitoring the temperature change of four sections of pylons of Zhanjiang Bay Bridge in the construction phase, DONG analyzed and summarized the temperature change rule of tower, with a manhole in the winter, and presented a one-dimensional and nonlinear temperature distribution expression along the thickness direction [1]. Based on the analysis of temperature stress under the action of the sunshine temperature, the internal temperature field of bridge tower is approximately obtained by the following formula [2]:

$$
T_{i a}=T_{o a}+1.5
$$

$T_{o a}$ represents the average atmospheric temperature on the structural surface. While analyzing the temperature field of concrete structure under the sun, researchers considered the random distribution of meteorological parameters, and ignored the component of longitudinal temperature gradient,

*Address correspondence to this author at the Middle of South 2nd ring road, School of Highway, Chang'an University, Xi'an 710064, China; Tel:+8629-82336336; E-mail: niuyanwei@chd.edu.cn and compute the temperature field according to plane problems [3]. As for a suspension bridge, researchers tested the tower wall temperature, inside and outside the environment, and the surface temperature field of concrete hollow tower in the three seasons [4]. They analyzed the varying regularity of different temperature load with the time. Under the adverse temperature difference, they computed and analyzed temperature gradient mode on the tower wall thickness direction and length-width direction. Researchers chosen three typical seasons, tested the surface temperature field of concrete bridge towers of a suspension bridge, and obtained the difference curve of changed temperature in the direction of wall thickness in three seasons, ignoring the temperature changes in the direction of height [5]. According to the temperature data measured previously, the rule of temperature change was simulated and temperature field and effect of temperature on the main tower of concrete cable-stayed bridge under different external environments influence, were analyzed [6]. In conclusion, spatial temperature distribution of concrete bridge tower is mostly associated with the bridge tower with hollow section and the previous studies focussed mainly on one-dimensional nonlinear distribution patterns. Space temperature distribution of large cross-section solid bridge tower of extradosed cable-stayed bridge needs further research. In this study, based on the analysis of temperature field in bridge tower model, researchers have provided a calculation method of space temperature field of concrete solid bridge tower, verified the correctness of the algorithm, computed space temperature distribution of large cross-section solid bridge tower, analyzed the features of space temperature distribution change with time, and provided reliable temperature effect parameters for the bridge tower. 
2. THE CALCULATION METHOD OF SPACE TEMPERATURE FIELD OF SOLID BRIDGE TOWER

On the premise of reasonable assumptions, researchers ignored secondary factors influencing bridge tower temperature field, computed structural heat transfer boundary conditions, assumed the initial temperature, strived for the approximate solution of complex heat conduction differential equation, to obtain the internal temperature distribution of the bridge tower. The initial temperature is relatively easy to determine. According to the date of the year, researchers got a series of proper value. Heat transfer boundary condition of concrete structure includes two parts: (1) the intensity of solar radiation on the surface of the concrete structure; (2) convective heat transfer and radiation heat transfer between concrete structures with outside air or other objects.

\subsection{The Intensity of Solar Radiation on the Surface of Bridge Tower}

The intensity of solar radiation is the main factor affecting temperature field of concrete structure. Solar radiation is constantly reflected, absorbed and scattered by the various components in the atmosphere, when going through the atmospheric layer and reaching the earth surface. Therefore, the solar radiation reaching ground decays. Part of the solar radiation of scattering reaches the surface of the earth. So, the total solar radiation intensity on the structure of the ground is composed of the direct solar radiation intensity, the scattering radiation and ground reflection.

\subsubsection{The Direct Solar Radiation Intensity}

In the engineering practice, solar radiation intensity $\left(I_{D}\right)$, on the plane is perpendicular to the direction of the sun, can be approximately computed by using the formula (1):

$I_{D}=I_{0} 0.9^{t_{u} k_{a} m}$

where $I_{0} \longrightarrow$ is the solar constant, whose value changes according to the date within a year; $K_{a}-$ is the atmospheric relative pressure, which changes with altitude. $t_{u}-$ is the Linke turbidity coefficient [7], which changes with atmospheric conditions and seasons. The value can be calculated by the empirical formula (2):

$t_{u}=A_{t u}-B_{t u} \cos \left(\frac{360^{\circ} N}{365}\right)$

where $A_{t u}$ and $B_{t u}$ are the empirical parameters and respectively represent the value and range under different atmospheric conditions respectively; $N$ represents the ordinal number of days. $m-$ is the atmospheric optical mass, it is an important parameter representing the degree of solar radiation attenuation. World meteorological organization provides the empirical formula to compute atmospheric optical mass:

$m=\left[\sin \beta_{s}+0.150\left(\beta_{s}+3.885\right)^{-1.235}\right]^{-1}$

Where $\beta_{s} \longrightarrow$ is the solar altitude, it changes with latitude and longitude and is associated with date.

From the formulas (1) to (3), after determining the date and latitude and longitude of a certain place, solar radiation intensity, perpendicular to the plane in the direction of the sun, can be calculated. We can compute the direct solar radiation intensity based on arbitrary surface of the structures $\left(I_{D \varphi}\right)$, according to angle $(\varphi)$ in the direction of the sun's rays and the outer normal of the structure surface (formula 4). $\varphi$ is related to the latitude, longitude, the angle of structure surface and horizontal plane.

$$
I_{D \varphi}=I_{D} \cos \varphi
$$

The calculation results of direct solar radiation intensity on arbitrary surface of the structures $\left(I_{D \varphi}\right)$ may have positive or negative value. If $I_{D \varphi}$ is a positive value, we argue that the surface of the structures absorbs solar radiation. Otherwise, the direct solar radiation intensity on this surface is zero.

\subsubsection{The Scattering Radiation Strength}

The scattering strength is directly related to the radiation intensity. The stronger the direct radiation is, the lower the scattering intensity is. The scattering radiation of structure surface is irrelevant to surface azimuth but is related to the surface inclination. The scattering strength on horizontal plane $I_{d H}[8,9]$ can be computed by using the following formula (5).

$$
I_{d H}=\left(0.271 I_{0}-0.29 I_{D}\right) \sin \beta_{s}
$$

The sky scattering intensity on arbitrary oblique plane can be computed as follow:

$$
I_{d \beta}=\frac{1+\sin \beta_{n}}{2} I_{d H}
$$

\subsubsection{The Ground Reflection Intensity}

After the solar radiation reaches the earth surface, part of the solar radiation is reflected at the structure surface by ground. The intensity of the ground reflection $I_{r \beta}$ can be computed by using the formula (7):

$$
I_{r \beta}=\frac{1-\sin \beta_{n}}{2} r_{e}\left(I_{D} \sin \beta_{s}+I_{d H}\right)
$$

In the formula (7), $r_{e} \longrightarrow$ is the surface shortwave reflectivity, generally its value is 0.2 ; but for snow-covered ground, it is 0.7 .

The total radiation intensity on arbitrary structure surface $q_{\varphi}$ is computed as follows:

$q_{\phi}=I_{D \phi}+I_{d \beta}+I_{r \beta}$

\subsection{Convective Heat Exchange}

The solar radiation acts on concrete structures in the natural environment leading to the convective heat transfer in the meanwhile. In general, the structures dissipate or absorb heat in two ways, convection heat transfer and radiation heat transfer. When calculating the temperature of concrete field structures, researchers usually consider the two altogether by a factor- i.e. the total heat exchange coefficient $h$ [10].

$h=h_{c}+h_{x}=3.060 v+0.035 \Delta t+9.550$ 


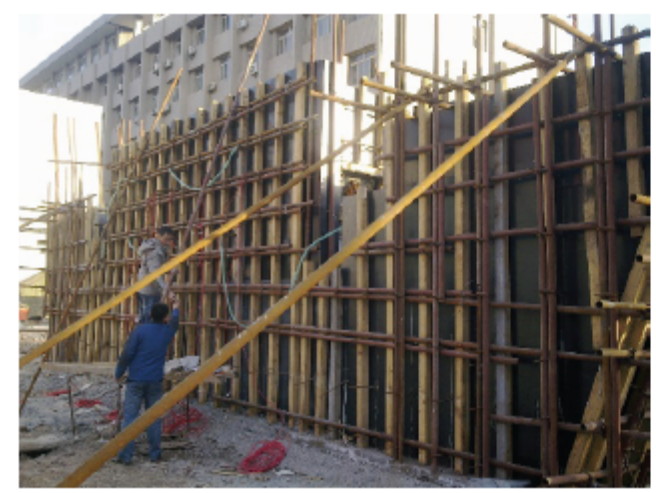

a. Install the sensor

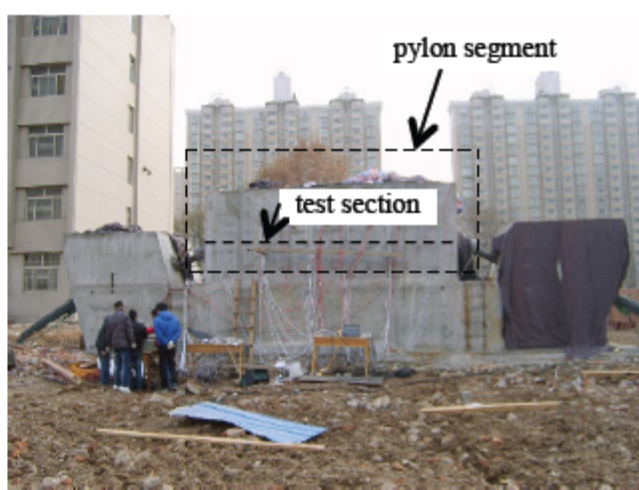

b. Test pylon segment

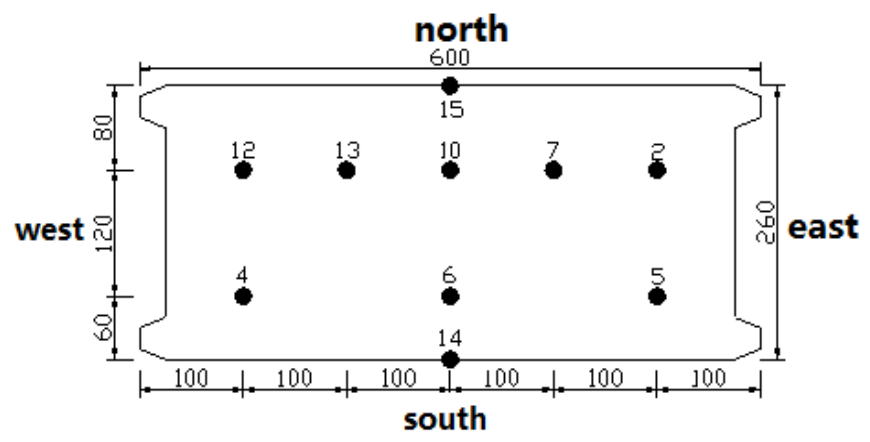

c. Test section of bridge tower and sensor layout

Fig. (1). General situations of test.

where $h_{c}-$ is the convective heat transfer coefficient, it is related to the natural wind speed $v ; h_{x} \ldots$ is the radiation heat transfer coefficient, which is affected by the temperature difference between concrete structure surface and air.

In conclusion, by inputting a series of parameters, such as the geographical latitude and longitude, the date of temperature field calculation, the angle of the bridge tower surface and the horizontal plane, wind speed, reflection coefficient, atmospheric relative pressure, and Linke turbidity, we can obtain the heat transfer boundary of concrete bridge towers. Then, we assume the initial temperature as the thermal boundary condition and compute spatial temperature distribution by using finite element model.

\subsection{Heat Conduction Computation}

As intensity of solar radiation and heat exchange coefficient of outside surface is obtained, heat conducts inside the pylon section. The speed and range of the heat effection is depend on the thermal conduct conductivity $\lambda$. For 2-D section, fomula (9) is commonly used to compute the temperature field inside the structure.

$\lambda\left(\frac{\partial^{2} T}{\partial x^{2}}+\frac{\partial^{2} T}{\partial y^{2}}\right)=\rho c \frac{\partial T}{\partial t}$

where $\lambda$ is thermal conductivity (unit: $\mathrm{W} \cdot \mathrm{m}^{-1} \cdot \mathrm{K}^{-1}$ ); $\rho$ is density (unit: $\mathrm{kg} / \mathrm{m}^{3}$ ); $c$ is the specific heat capacity $\left(\mathrm{J} \cdot \mathrm{kg}^{-1} \cdot \mathrm{K}^{-1}\right) . \quad T$ is unsteady temperature field, and $T=T(x, y, t), \mathrm{x}, \mathrm{y}$ represent transverse and longitudinal coordinates.

\section{EXPERIMENTAL VERIFICATION OF ALGO- RITHM}

In this paper, the theoretical value is compared with the test value - temperature field data of solid bridge tower of extradosed cable-stayed bridge is measured, in order to verify the correctness of temperature field calculation method.

\subsection{Temperature Field Test of Bridge Tower}

\subsubsection{General Situations of Test}

Test site is located in Chang'an University in Xi'an (34.23 degrees north latitude and 108.95 degrees east longitude). Longitudinal direction of bridge tower model is along east-west line. There are eight temperature sensors lying the cross sectionally. Two sensors measuring surface temperature are respectively set at the midpoint of north and south sides. Overall, there are ten temperature sensors out on which nine measure temperature distribution in the section and one test the environment temperature. The material of bridge tower is the reinforced concrete C50. Test data is collected in five consecutive sunny days, form January 23, 2013 to January 27, 2013. Tower bridge test model and sensor layout is shown in Fig. (2).

\subsubsection{The Actual Heat Transfer Boundary Conditions}

Sunrise and sunset time is about 8:00 and 18:00. When the sun is down, it is thought that there is no solar radiation, no scattering intensity and no ground reflection. The parameters related to the calculation are shown in Table $\mathbf{1}$. The solar radiation intensity on south surface of bridge tower in five consecutive days is shown in Fig. (2). 
Table 1. Calculation parameters.

\begin{tabular}{|c|c|c|}
\hline Parameters & Symbols & Value \\
\hline \hline Longitude & $J D$ & $108.95^{\circ}$ \\
\hline Latitude & $\phi$ & $34.23^{\circ}$ \\
\hline Number of days & $N$ & $23 \sim 27$ \\
\hline Angle of bridge tower surface and horizontal plane & $\beta_{n}$ & $A_{t u}=3.7, B_{t u}=0.5$ \\
\hline Linke turbidity coefficient & $t_{u}$ & 0.6 \\
\hline Atmospheric relative pressure & $k_{a}$ & 0.2 \\
\hline Reflection coefficient & $r_{e}$ & \\
\hline
\end{tabular}

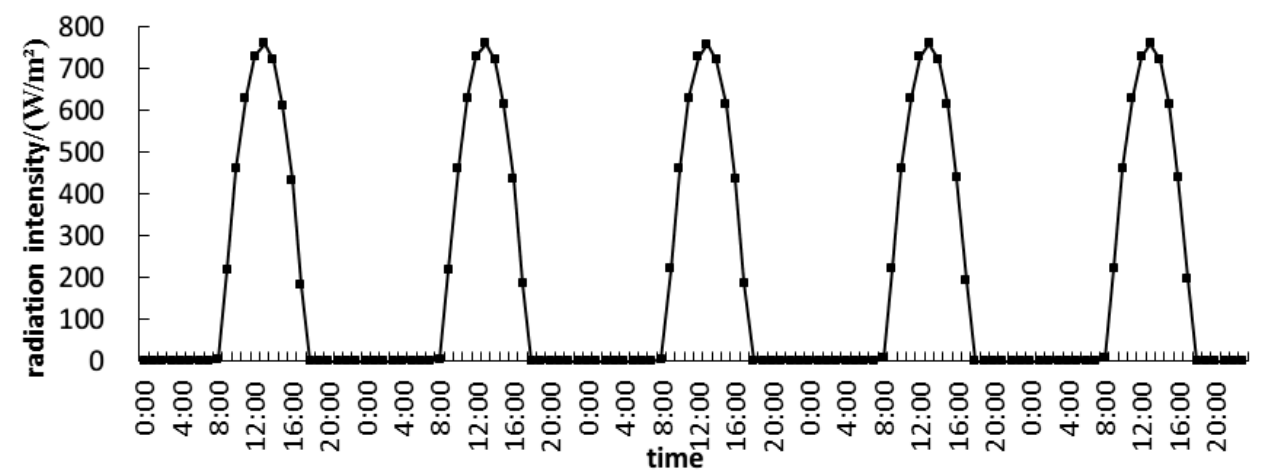

Fig. (2). Solar radiation intensity on south surface in five consecutive days.

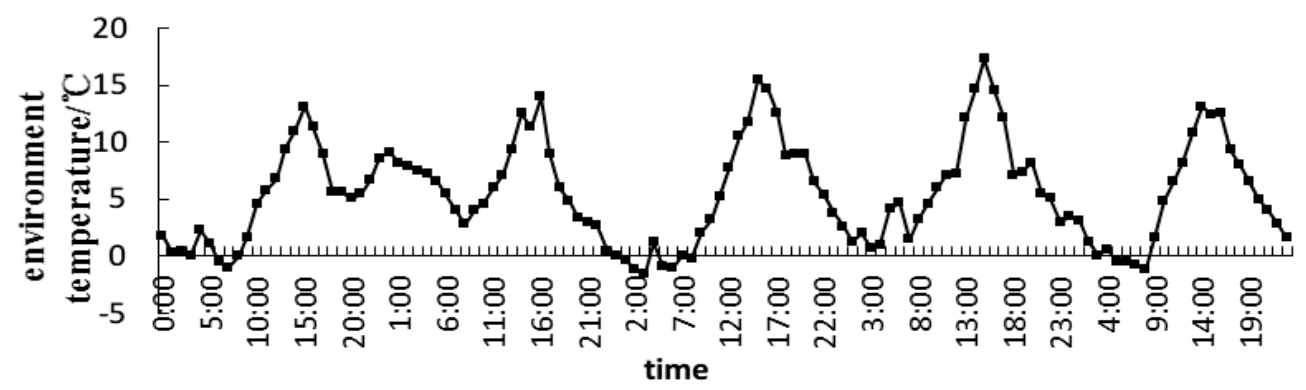

Fig. (3). Environment temperature in five consecutive days.

According to the meteorological data collected in Xi'an, average wind speed is $4.4 \mathrm{~m} / \mathrm{s}$ in the test period. We ignored the fact that the temperature difference of the concrete structure surface and air have an influence on the radiation heat transfer coefficient. The convection coefficient is 23.074 $\mathrm{W} /\left(\mathrm{m}^{2} \cdot{ }^{\circ} \mathrm{C}\right)$. Both convection coefficient and environment temperature are necessary to simulate the convection heat transfer. The environment temperature is measured by the sensor in the air, which is not affected by the solar ray. The environment temperature in five consecutive days is shown in Fig. (3). Considering the test is operated in January, we assume the initial temperature is $0^{\circ} \mathrm{C}$ which is consistent with the actual situation.

\subsection{Finite Element Model}

Concrete solid bridge tower belongs to the slender members whose longitudinal size is larger than the lateral size. In this paper, we assume that the temperature distribution in the cross section is two-dimensional. Because the change of temperature field in the direction of height is small, it can be ignored. In the finite element model, we used 8-node quadrilateral plane strain element to simulate the solid bridge tower section. There are 7550 elements and 23081 nodes in the model. Heat flux is put on the cross section boundary. On the convection boundary, we simulate intensity of solar radiation and convection heat transfer. The initial node temperature is $0^{\circ} \mathrm{C}$. Entity model of solid cross section of bridge tower is shown in Fig. (4).

\subsection{Comparison of the Theoretical Value and Experi- mental Value}

By comparing the finite element analysis results to the experimental data, there are two conditions found to be met: (1) in analysis period, the heat transfer boundary in finite 
element must be consistent with the actual situation; (2) the section temperature distribution based on starting point theory must be consistent with the test results. Through the finite element calculation software, we computed the temperature distribution of 5 days and found that the section temperature field is basically stable and consistent with the actual temperature field of the fifth day. So, we compared calculation results with the test data of the fifth day. We should however, consider that the concrete thermal parameters have a greater influence on the calculation results. GB 501761993 civil building thermal design code stipulates: heat conductivity of reinforced concrete $\lambda=1.74 \mathrm{~W} /(\mathrm{m} \cdot \mathrm{K})$; specific heat capacity $\mathrm{c}=920 \mathrm{~J} /(\mathrm{kg} \cdot \mathrm{K})$ [11]. GB 50010-2010 Code for Design of Concrete Structures the Part 4 4.1.8 rule stipulates: heat conductivity of reinforced concrete $\lambda=2.94$ $\mathrm{W} /(\mathrm{m} \cdot \mathrm{K})$; specific heat capacity $\mathrm{c}=960 \mathrm{~J} /(\mathrm{kg} \cdot \mathrm{K})[12]$. In this study, two kinds of thermal parameters were used to calculate the results respectively, then we compared the accuracy of the calculation results.

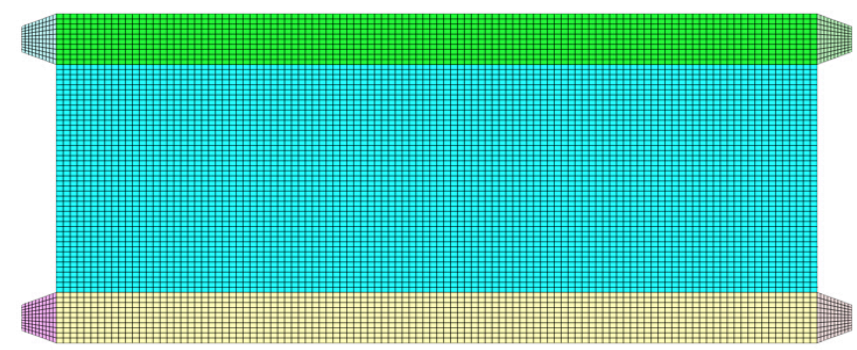

Fig. (4). Model of solid cross section of bridge tower.

There are 4 representative channels. The comparison of theoretical value and experimental value is shown in Fig. (5). Value 1 is the result calculated by standard Code for Design of Concrete Structures. Value 2 is the result calculated by civil building thermal design code. The trend and value of the four channels' data and theoretical calculation results are basically similar. The result calculated by thermal parameters in standard Code for Design of Concrete Structures meets the test temperature field requirements even more appropriately.

In order to ensure the reasonable calculation results, we analyzed the average error of ten channels within 24 hours (Table 2). After the temperature field gets stable, in the later 24 hours, the average error of channel 14 test value and calculated value is about $24.97 \%$. Channel 15 average error is about $33.77 \%$. In the cross section, the maximum average error of test value and calculated value is $28.93 \%$ for 7 channels, and minimum maximum average error is $3.07 \%$ for 5 channels.

The errors of calculated values and each channel's measured values at sunrise and sunset moment (Fig. (6)) were analyzed. The results show that: the average error of each channel's test value and calculation value at corresponding position is within $21.38 \%$ at $8: 00$ and $18: 00$. Because the error is within the engineering permissible range, this kind of calculation method is reasonable to compute temperature field of concrete bridge towers.

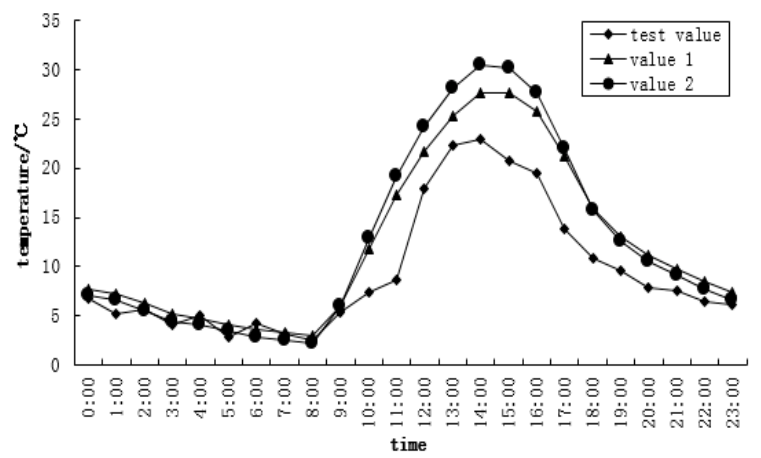

a. Channel 14

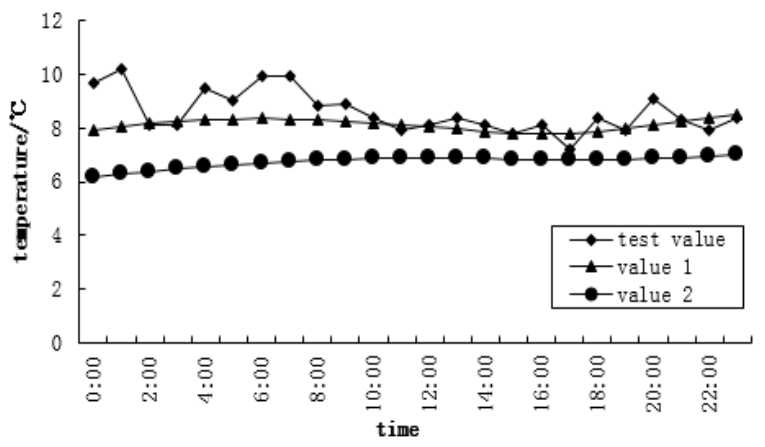

b. Channel 5

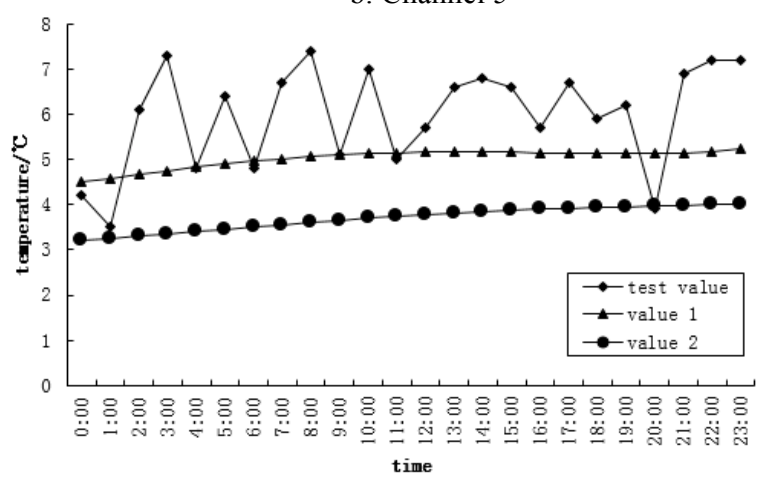

c. Channel 12

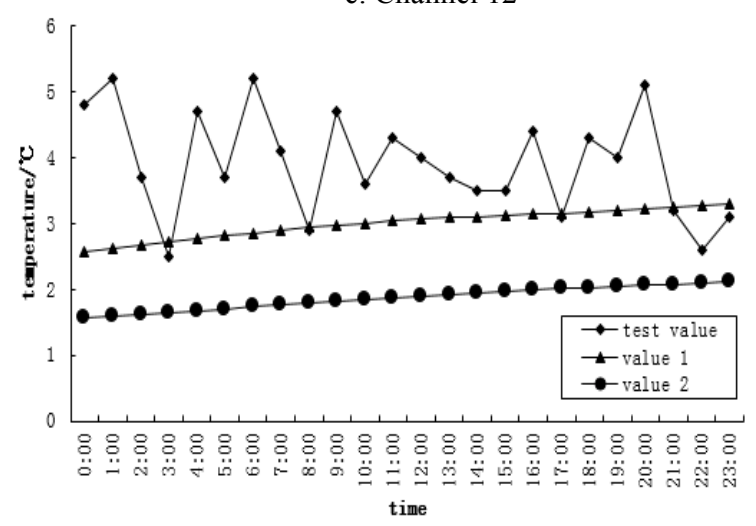

d. Channel 10

Fig. (5). Comparison of theoretical value and experimental value of 4 representative channels. 

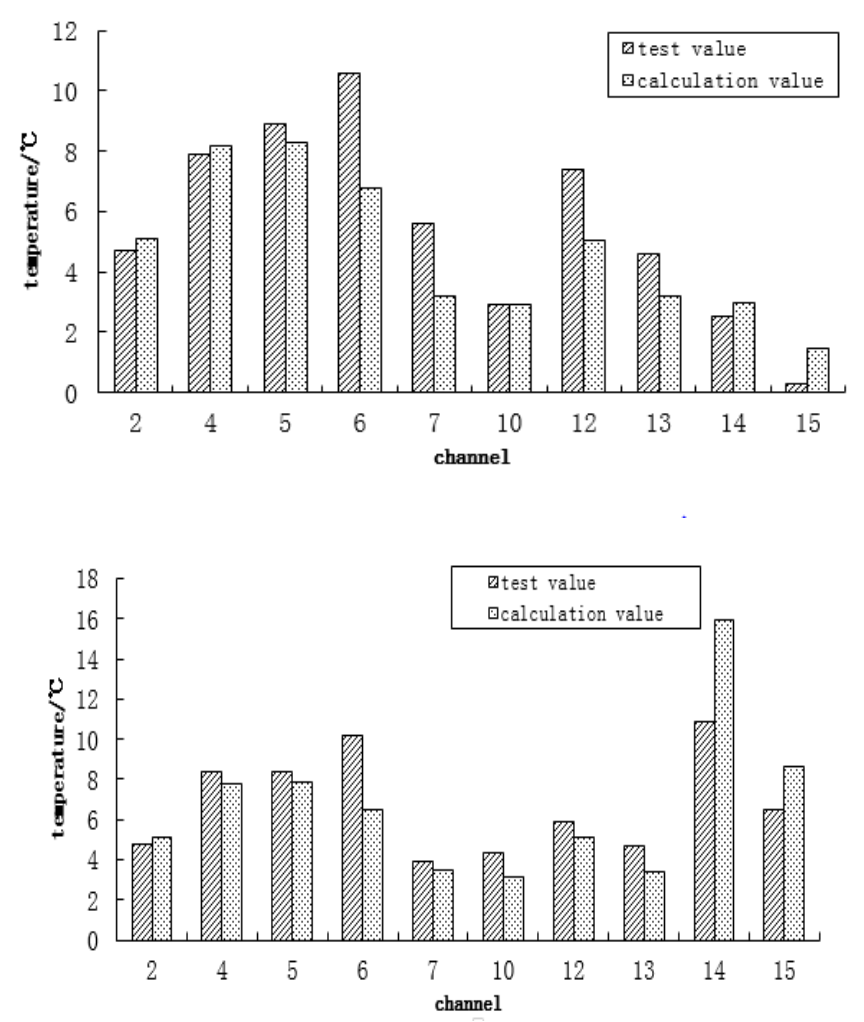

Fig. (6). Calculated values and measured values at sunrise and sunset.

Table 2. Average error of each channel.

\begin{tabular}{|c|c|c|c|c|c|c|c|c|c|c|}
\hline Channel number & $\mathbf{1 4}$ & $\mathbf{1 5}$ & $\mathbf{5}$ & $\mathbf{6}$ & $\mathbf{4}$ & $\mathbf{2}$ & $\mathbf{7}$ & $\mathbf{1 0}$ & $\mathbf{1 3}$ & $\mathbf{1 2}$ \\
\hline \hline Average error (\%) & 24.97 & 33.77 & 3.07 & 27.90 & 13.25 & 5.46 & 28.93 & 18.79 & 28.21 & 12.78 \\
\hline
\end{tabular}

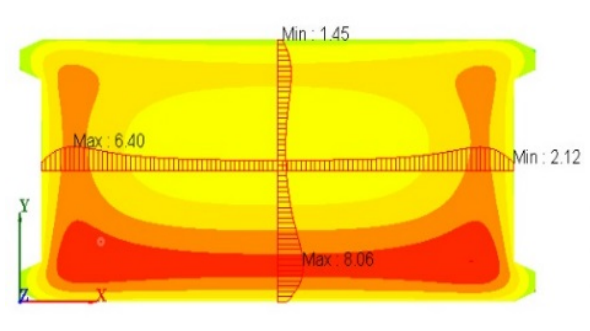

a. Temperature distribution at 8:00

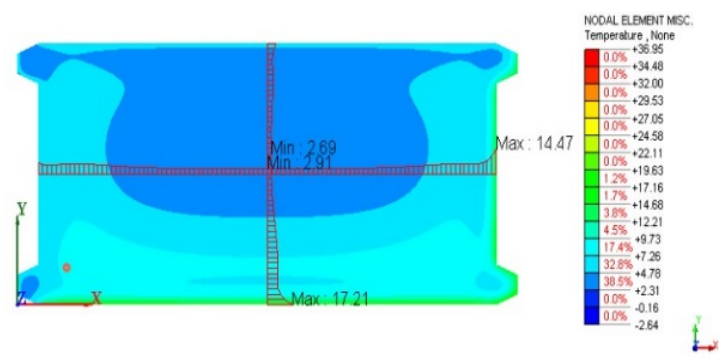

c. Temperature distribution at 11:00

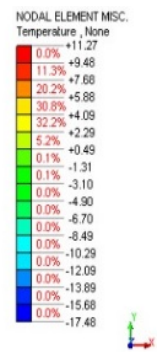

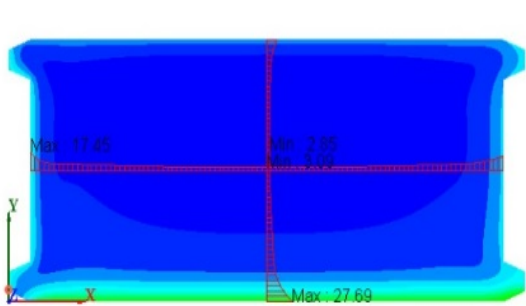

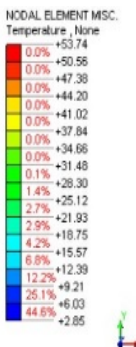

b. Temperature distribution at 15:00

d. Temperature distribution at 16:00

Fig. (7). Section temperature distribution at different moments. 


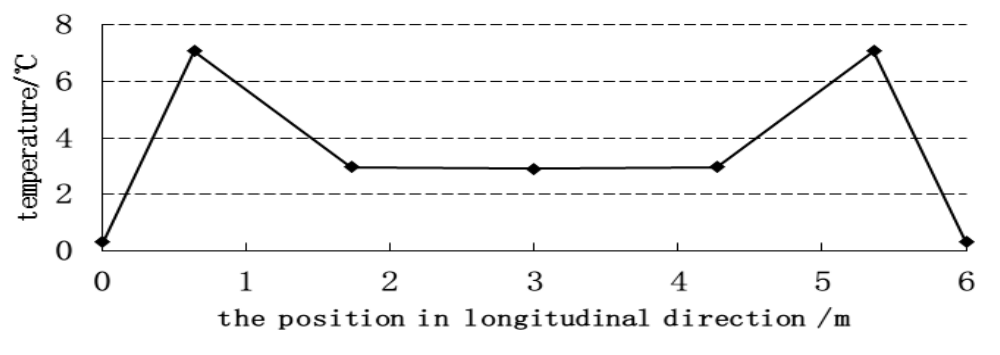

Fig. (8). The temperature distribution curve when the maximum negative temperature difference appears in the longitudinal direction.

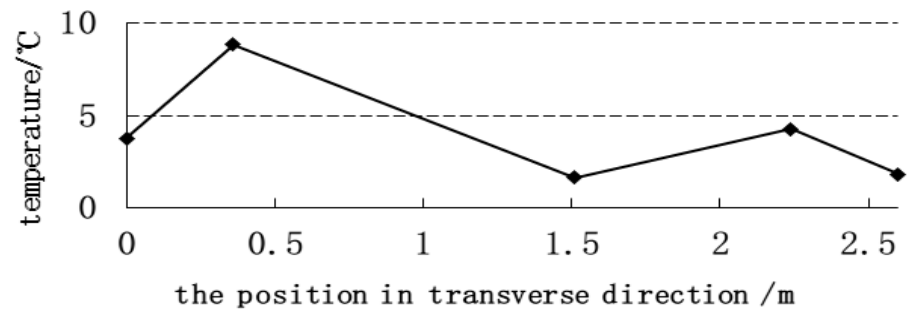

Fig. (9). The temperature distribution curve when the maximum negative temperature difference appears in the transverse direction.

\section{SPATIAL TEMPERATURE DISTRIBUTION PAT- TERN OF SOLID BRIDGE TOWER}

The solar temperature field of concrete bridge tower is similar to concrete box girder temperature field. Both are unsteady temperature fields, whose characteristics change with time. In this study, we analyzed the temperature distribution in the later 24 hours, after the temperature field gets stable. The result shows that the temperature distribution, both in longitudinal and lateral directions, basically remains the same during the night. Its characteristics are as follows: the surface temperature is relatively low; temperature increased first and then decreased from outside to inside; the highest temperature appears at about $20 \mathrm{~cm} \sim 40 \mathrm{~cm}$ away from the surface; the maximum negative temperature difference appears at sunrise (Fig. 7a); and the maximum negative temperature difference in longitudinal and transverse directions is $5.1^{\circ} \mathrm{C}$ and $4.2^{\circ} \mathrm{C}$ respectively. In the daytime, the temperature distribution is basically same in the transverse direction. Its characteristics are as follows: the highest temperature appears on the surface; the temperature sharply decreases within the scope of about $20 \mathrm{~cm}$ to $40 \mathrm{~cm}$ inwards; at 15:00 PM, the maximum positive temperature difference appears in the transverse direction (Fig. 7)) and its value is about $20{ }^{\circ} \mathrm{C}$. At 11:00 and 16:00, the east and west maximum positive temperature differences appear in the longitudinal direction (Fig. 7c \& d) and their value is $8.6^{\circ} \mathrm{C}$ and $13.1^{\circ} \mathrm{C}$ respectively.

Under the act of positive temperature gradient, as for solid concrete bridge towers, all the parts of the concrete bridge towers are in different state of strain. The deformation of external concrete is restrained by the internal concrete, so tensile stress appears in the internal concrete. But since the internal concrete has a larger area and is wrapped by external concrete, the tensile stress caused by positive temperature gradient has a small effect on the bridge tower. On the contrary, negative temperature gradient will exert a large tensile stress on the surface of solid bridge tower. In this paper, un- der the maximum negative temperature difference, we simulate the temperature distribution both in longitudinal and transverse directions (Figs. 8 \& 9).

The equation for temperature distribution curve in the longitudinal direction is as follows:

$t= \begin{cases}10.594 x+0.307 & x \in[0.00,0.64] \\ -3.042 x+8.237 & x \in(0.64,1.73] \\ -0.045 x+3.052 & x \in[1.73,3.00]\end{cases}$

The graphics, in the range $x \in(3,6)$, and graphics, in the range $x \in(0,3)$, are symmetrical.

The equation for temperature distribution curve in the transverse direction is:

$$
t= \begin{cases}14.057 y+3.784 & y \in[0.00,0.36] \\ -5.324 y+9.703 & y \in(0.36,1.51] \\ 2.804 y-1.993 & y \in[1.51,2.24) \\ -9.024 y+25.307 & y \in(2.24,2.60]\end{cases}
$$

\section{CONCLUSION}

The method to calculate the space temperature field of concrete solid bridge tower is put forward systematically. By defining a series of parameters, such as the geographical latitude and longitude, the date of temperature field calculation, the angle of the bridge tower surface and the horizontal plane, wind speed, reflection coefficient, atmospheric relative pressure, and Linke turbidity, we can obtain the heat transfer boundary value for the concrete bridge towers. Then, by assuming the initial temperature as the thermal boundary condition, the spatial temperature distribution was computed by using thermal analysis function of finite element software.

The comparison of calculation value and experimental value of temperature field of the bridge tower model is pre- 
sented. After a stable temperature field is maintained, in the later 24 hours, the average error of each channel is within $33.77 \%$. The average error of all of channels is within $21.38 \%$ at sunrise and sunset. The calculation results are more accurate and the numerical computation method of concrete bridge tower temperature is reasonable.

The maximum negative temperature difference appears at sunrise time, and the maximum negative temperature differences in longitudinal and transverse directions are $5.1^{\circ} \mathrm{C}$ and $4.2{ }^{\circ} \mathrm{C}$ respectively. At 15:00 PM, the maximum positive temperature difference appears in transverse direction, and its value is about $20^{\circ} \mathrm{C}$. We simulate the temperature distribution both in longitudinal and transverse directions, under the maximum negative temperature difference. Finally, the temperature distribution curve equation is derived, which can provide the temperature effect parameter for the bridge tower.

\section{CONFLICT OF INTEREST}

The authors confirm that this article content has no conflict of interest.

\section{ACKNOWLEDGEMENTS}

The authors would like to gratefully acknowledge the support from National Natural Science Foundation of PR China (51208056), Foundation of Loess Region Key Laboratory of Transportation Ministry (KLTLR-Y12-7) and Shanxi Transportation Science and Technology Foundation (11-224). The Fundamental Research Funds for the Central Universities (310821161013).

\section{REFERENCES}

[1] G. Z. Dong, "Analysis of cable-stayed bridge pylon temperature field test”, Gangzhou Architecture, vol. 2, pp. 32-36, 2006.

[2] H. Y. Tang, "Study about temperature stress of prestressed concrete bridge tower of cable-stayed bridge in the sunshine", Journal Nanchang University, vol. 30, no. 3, pp. 275-278, 2008.

[3] J.Z. Xiao, "Analysis of sunshine temperature effect of concrete structure based on meteorological parameters", China Civil Engineering Journal, vol. 43, no. 4, pp. 30-36, 2010.

[4] X. Ren, "The study about time-varying analysis of temperature field of concrete bridge towers and the temperature gradient mode", Xi'an: Xi'an University of Technology and School of Civil Engineering, 2012.

[5] Z. L. Liu, "Evaluation on developing level of unban agglomeration derived from resources exploration", Journal of Applied Sciences, vol. 13, no. 21, pp. 4702-4707, 2013.

[6] Z. M. Mo, "Analysis of influence factors about temperature effect on main tower of concrete cable-stayed bridge and wind speed", Technology and Engineering, vol. 13, no. 25, pp. 7591-7594, 2013.

[7] M. M. Elbadry and A. Ghali, "Temperature variations in concrete bridges", Journal of the Structural Engineering, vol. 109, no. 10, pp. 2355-2374, 1983.

[8] S. S. Li, Solar Physics. Beijing: Capital Normal University Press, 1996.

[9] A. M. Sayigh, Solar Energy Engineering. Beijing: Science Press, 1984.

[10] J. R. Zhang and Z. Q. Liu, "Pneumatic experimental study about concrete convection heat transfer coefficient", Journal of Civil Engineering (in Chinese), vol. 39, no. 9, pp. 39-42, 2006.

[11] China Academy of Building Research, Thermal Design Code for Civil Building (GB 50176-1993). Beijing: China Planning Press, 1993.

[12] Ministry of Housing and Urban-Rural Development of China, Code for Design of Concrete Structures (GB 50010-2010). Beijing: China Architecture \& Building Press, 2010.

Received: July 19, 2014

Revised: September 01, 2014

Accepted: November 12, 2014

(C) Niu et al.; Licensee Bentham Open.

This is an open access article licensed under the terms of the (https://creativecommons.org/licenses/by/4.0/legalcode), which permits unrestricted, noncommercial use, distribution and reproduction in any medium, provided the work is properly cited. 